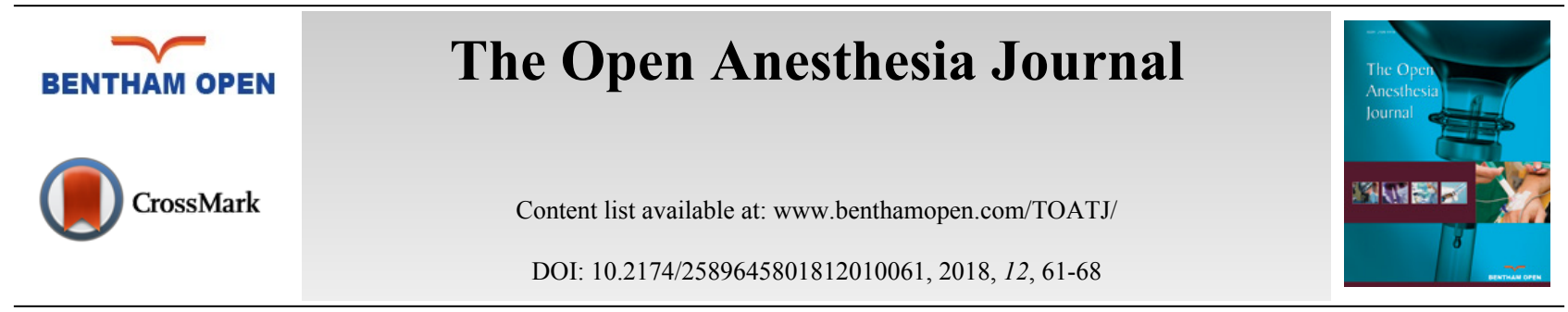

RESEARCH ARTICLE

\title{
Increased Nociception Following Administration of Different Doses of Tranexamic Acid in Adolescent Idiopathic Scoliosis Surgery
}

\author{
Ashraf Nabil Saleh and Raham Hasan Mostafa ${ }^{*}$ \\ Faculty of Medicine, Ain Shams University, El-hay El-Sabee, Nasr City, Cairo, Egypt
}

Received: May 28, 2018

Revised: September 5, 2018

Accepted: September 10, 2018

\section{Abstract: \\ Background:}

The inhibitory effect of Tranexamic Acid (TXA) on $\gamma$-aminobutyric acid and glycine receptors of spinal dorsal horn neurons which leads to pain arousal, has been highlighted recently in animal studies. Such findings would elicit concerns about adverse effects of TXA as a routine agent used to reduce perioperative blood loss.

\section{Objectives:}

This study aimed to evaluate the effect of different doses of TXA on analgesic requirements in adolescent patients undergoing elective single-stage posterior spine fusion surgery for idiopathic scoliosis.

\section{Patients and Methods:}

This prospective, randomized, double-blinded study comprised 75 patients who were randomly allocated to one of three groups. Each group comprised 25 patients. In group C (Control), patients received normal saline. While in group HD (High Dose), patients received TXA with a loading dose of $50 \mathrm{mg} / \mathrm{kg}$ and maintenance dose of $20 \mathrm{mg} / \mathrm{kg} / \mathrm{h}$ and patients in group LD (Low Dose) received TXA with a loading dose of $10 \mathrm{mg} / \mathrm{kg}$ and maintenance dose of $1 \mathrm{mg} / \mathrm{kg} / \mathrm{h}$. The total intraoperative fentanyl dose was calculated for each patient which we used as a measure of the patients' nociception level.

\section{Results:}

Group HD patients' required the highest dose of fentanyl compared to those in LD group (mean of $60 \mu \mathrm{g}$ versus $27 \mu \mathrm{g}$ ). Patients in group $\mathrm{C}$ received no extra intraoperative narcotic doses and experienced the longest duration of surgical procedure. These results showed high statistically significant difference $(p<0.001)$.

\section{Conclusion:}

Intraoperative administration of TXA increases the analgesic requirement during elective single stage posterior spine fusion surgery which likely reflects an increase in patients' intraoperative nociception.

Keywords: Adverse effects, Bleeding, Fentanyl, Idiopathic Scoliosis, Nociception, Tranexamic Acid.

\section{INTRODUCTION}

The surgical management of scoliosis is generally indicated to improve patient's posture through correct of spinal curvatures and more importantly to prevent the occurrence of long-term pulmonary complications. Such surgical interventions can result in a large amount of blood loss due to rich venous plexus and a large raw area of decorticated bony tissue [1]. Measures to reduce blood loss in such surgeries have included the application of improved surgical techniques, proper patient positioning in addition to controlled hypotension and aggressive management of hypothermia

* Address correspondence to this author at the Faculty of Medicine, Ain Shams University, El-hay El-Sabee, Nasr City, Cairo, Egypt; Tel: 002/01222530020; E-mail: rahamhasan@yahoo.com 
and coagulopathies [2,3]. The use of powerful antifibrinolytic agents such as Tranexamic Acid (TXA) has gained wider acceptance in major cardiovascular and orthopedic surgeries in which huge blood loss is anticipated [4]. TXA is a synthetic lysine analogue that acts by inhibition of plasminogen activation [5]. The utilization of TXA for adolescents and adults experiencing spinal corrective surgeries for spinal disfigurement has turned into the standard of care in several organizations [6]. Notwithstanding, there remains a scarcity of uniform information as regards to the optimum dose and timing of TXA without developing adverse effects. A recent animal study highlighted that this inhibitory effect on such receptors in the spinal dorsal horn neurons can lead to pain arousal [7]. Accordingly, intraoperative TXA usage might increase the amounts of analgesics needed during surgeries [8].

Therefore, this study aimed at evaluating the effect of different doses of TXA on analgesic requirements in adolescent Egyptian patients undergoing elective single stage posterior spine fusion surgery for Adolescent Idiopathic Scoliosis (AIS).

\section{PATIENTS AND METHODS}

\subsection{Study Design and Setting}

This was a prospective, randomized, double-blinded study that was conducted in Ain Shams University Hospital (ASUH) through the period from April 2017 to November 2017.

\subsection{Study Population}

The study comprised 75 patients who participated in the study after informed consents have been obtained from their parents or their legal guardians. The work was approved by the Ethics committee of ASUHs and in accordance with the ethical guidelines of the Declaration of Helsinki, 1975. Eligibility criteria for this study included patients $12-18$ years of age, American Society of Anesthesiologists Physical Status (ASA PS) class I and II, who were scheduled for elective single stage posterior spine fusion surgery for idiopathic scoliosis under general anesthesia. Patients with known renal or hepatic disorders, bleeding diathesis, thromboembolic event one year prior to surgery, preoperative anemia (hemoglobin $<10 \mathrm{gm} \%$ ), thrombocytopenia, International Normalized Ratio $>1.4$, or those with severe pulmonary disease, neuromuscular diseases, congenital or syndromic scoliosis or intra-spinal malformations were not eligible for this study. Additionally, patients who suffered from intraoperative surgical complications that led to unexpected blood loss or those who had the surgical performed via either combined anterior and posterior spinal fusions or the anterior procedure were also exempted from the study. It is to be noted that all surgeries were done by the same surgeons and anesthesiologists working at ASUH- Assembled Theater - Orthopedics operating rooms.

\subsection{Data Collection}

Demographic characteristics and relevant clinical data were collected for each patient by the aid of a standardized data collection form.

\subsection{Preoperative Preparation}

All patients were admitted to ASUH one day before the operation. A preoperative visit was directed to explain the manoeuvre, obtain history and check relevant investigations which included complete blood count, liver and renal function tests, coagulation profile, random blood sugar and serum electrolytes. In addition to baseline Electrocardiogram (ECG), chest X ray, pulmonary function test and echocardiogram were obtained. Patients' Heart Rate (HR) and Blood Pressure (BP) were recorded.

In the pre-anesthetic room, a peripheral intravenous line was inserted and midazolam $0.01 \mathrm{mg} / \mathrm{kg}$ was administrated.

\subsection{Patients' Randomization, Intraoperative Interventions and Management}

Patients were randomly allocated in one of three groups by a computer-generated random numbers list and the use of opaque sealed envelopes. Each group comprised 25 patients.

In Group C (control), patients received normal saline. While in the other two groups; group HD (High Dose) and group LD (Low Dose); patients received Intravenous (IV) TXA with different loading and maintenance doses. Loading doses of either $50 \mathrm{mg} / \mathrm{kg}$ or $10 \mathrm{mg} / \mathrm{kg}$ were administered to patients in group HD and group LD, respectively, over a period of 30 -minutes before skin incision. Continuous infusion at a rate of either $20 \mathrm{mg} / \mathrm{kg} / \mathrm{h} \mathrm{or} 1 \mathrm{mg} / \mathrm{kg} / \mathrm{h} \mathrm{was}$ administered to patients in group HD and group LD, respectively, after skin incision through the end of the procedure 
and skin closure. This dosing regimen followed current literature and guidelines [9 - 11].

An anesthesiology technician prepared the IV solution to be administered, based on the patient's assigned group, handed it to the investigating anesthesiologist and had no role in patient's assessment. The patients, their parents, the investigating anesthesiologist, the surgeon, and the Post Anesthesia Care Unit (PACU) nurse remained blinded to the groups.

General anesthesia induction and maintenance were achieved by means of standard agents. Namely, propofol was first administered at a dose of $2 \mathrm{mg} / \mathrm{kg}$ followed by fentanyl at a dose of $1 \mu \mathrm{g} / \mathrm{kg}$ and endotracheal intubation was facilitated with atracurium $0.5 \mathrm{mg} / \mathrm{kg}$ as a neuromuscular blocker. After tracheal intubation the patient was positioned prone, ensuring that the eyes, nose and abdomen were free of pressure and there was no undue compression to the vessels or hindrance to respiration. Anesthesia was maintained with isoflurane 1-2 MAC and atacurium $0.1 \mathrm{mg} / \mathrm{kg}$ given every 20 minutes. End tidal $\mathrm{CO}_{2}$ was kept between 35-40 mmHg. Intraoperative monitoring included noninvasive BP, HR, ECG, pulse oximetry, capnography and urine output. To fulfill the primary objective of this study, patients' vital signs such as HR, Systolic BP (SBP), and Diastolic BP (DBP) values were recorded preoperatively and at different timings for 120 minutes following induction of anesthesia.

Fentanyl infusion at a constant rate of $0.5 \mu \mathrm{g} / \mathrm{kg} / \mathrm{h}$ was being used in order to control intraoperative nociception which was interpreted by elevation of BP \& HR. Bolus doses of $25 \mu \mathrm{g}$ were being introduced if required so as to keep HR and BP maintained within $20 \%$ of their baseline values (which were previously determined at the onset of operation and on the day of hospital admission). In addition, ephedrine was used whenever systolic BP dropped below $80 \mathrm{mmHg}$. The total dose of intraoperative fentanyl was calculated for each patient.

After a wake-up test was successfully completed, a single bolus dose of $5 \mathrm{mg}$ morphine (IV) was given with subsequent cessation of the fentanyl infusion 30 minutes after morphine's administration. The following clinical parameters were also recorded:

- Patients body weight, and ASA PS classification.

- Duration of surgery (time from skin incision till removal of surgical drapes).

- The total amount of intraoperative blood loss. This was calculated by summing the volume of blood collected in suction bottles and the weight of gauze.

Patients were extubated at the end of surgery and observed in the PACU. Any cardiac, pulmonary, renal vascular or neurological complications that occurred during the $1^{\text {st }}$ postoperative day were documented. Also, postoperative analgesic consumption during $1^{\text {st }}$ postoperative day was measured and documented. Postoperative analgesic plan was: fixed dose of paracetamol $10 \mathrm{mg} / \mathrm{kg} / 6$ hours (IV) in addition to $0.5 \mathrm{mg} / \mathrm{kg}$ intravenous pethidine on demand (Not to exceed $100 \mathrm{mg}$ pethidine/day, and at least 4 hours should pass after each dose of pethidine).

\subsection{Sample Size Determination}

A sample size of 75 cases ( 25 cases per group) was found satisfactory to detect an effect size of 0.4 (a medium effect size) using omnibus Analysis of Variance (ANOVA) test with level of significance of 0.05 and power of 0.80 .

\subsection{Statistical Analysis}

Data were analyzed using SPSS 21.0 for Windows (SPSS, Chicago, IL, USA). Qualitative data were presented as number and percentages while quantitative data were presented as mean, standard deviations and ranges. ANOVA was used to compare the three groups for quantitative parametric data with post-hoc Tukey's test performed if there was a significant difference among the groups. Comparison between two groups with qualitative data was done using Chisquare. $p$-value was considered as the following: $p>0.05$ : non-significant, $p<0.05$ : significant and $p<0.01$ : highly significant.

\section{RESULTS}

The study participants were 32 females (42.7\%) and 43 males (57.3\%). Relevant demographic and clinical data are shown in Table 1. There was no statistically significant difference between the 3 study groups as regards any of the patients' recorded characteristics. 
Table 1. Demographic and clinical data of all study participants $(n=75)$.

\begin{tabular}{|c|c|c|c|c|}
\hline Variables & $\begin{array}{c}\text { Group C } \\
(n=25)\end{array}$ & $\begin{array}{c}\text { Group LD } \\
(n=25)\end{array}$ & $\begin{array}{c}\text { Group HD } \\
(n=25)\end{array}$ & $p$-value \\
\hline Age (years) & $\begin{array}{c}14.6 \pm 2.16 \\
\mathrm{CI}=13.8-15.6\end{array}$ & $\begin{array}{c}14.6 \pm 2.1 \\
\mathrm{CI}=13.7-15.47\end{array}$ & $\begin{array}{c}14.6 \pm 2.07 \\
C I=13.8-15.54\end{array}$ & 0.988 \\
\hline \multicolumn{5}{|c|}{ Sex } \\
\hline Female & $11(44 \%)$ & $11(44 \%)$ & $10(40 \%)$ & \multirow{2}{*}{0.947} \\
\hline Male & $14(56 \%)$ & $14(56 \%)$ & $15(60 \%)$ & \\
\hline Body Weight (kg) & $\begin{array}{c}39.4 \pm 4.3 \\
\mathrm{CI}=36.77-42.8\end{array}$ & $\begin{array}{c}39 \pm 3.97 \\
\mathrm{CI}=36.5-42.28\end{array}$ & $\begin{array}{c}39.1 \pm 2.5 \\
\mathrm{CI}=36.75-42.25\end{array}$ & 0.993 \\
\hline \multicolumn{5}{|c|}{ ASA Physical Status } \\
\hline $\mathrm{I}$ & $16(64 \%)$ & $14(56 \%)$ & $15(60 \%)$ & \multirow{2}{*}{0.8} \\
\hline II & $9(36 \%)$ & $11(44 \%)$ & $10(40 \%)$ & \\
\hline Cobb's Angle & $\begin{array}{c}43.6^{\circ} \pm 3.69 \\
\mathrm{CI}=42.19-45.31\end{array}$ & $\begin{array}{c}43.6^{\circ} \pm 3.69 \\
C I=42.08-45.12\end{array}$ & $\begin{array}{c}43.8^{\circ} \pm 3.62 \\
\mathrm{CI}=42.3-45.16\end{array}$ & 0.975 \\
\hline \multicolumn{5}{|c|}{ PFT } \\
\hline Normal & $21(84 \%)$ & $21(84 \%)$ & $21(84 \%)$ & \multirow{2}{*}{1} \\
\hline Mild Restrictive & $4(16 \%)$ & $4(16 \%)$ & $4(16 \%)$ & \\
\hline
\end{tabular}

Data are presented as mean \pm SD and as mean $(95 \% \mathrm{CI})$ for continuous variables and as number (percentage) for categorical variables ASA: American Society of Anesthesiologists, PFT: Pulmonary Function Test

Similarly, no significant differences had been observed between the 3 groups of patients as regards the hemodynamic parameters recorded before anesthesia induction and at various times up to 120 minutes (Figs. 1, 2 and 3). However, there were high statistical significant differences between the groups as regards the duration of surgical procedure, the total intraoperative blood loss and fentanyl consumption. The HD group showed shortest surgical duration (mean of $128.3 \mathrm{~min} ; p<0.001$ ) and least blood loss (mean of $181.25 \mathrm{ml} ; p<0.001$ ) when compared to the LD group and control group. Also, the LD group when compared with the control group showed significant shorter duration (mean of $188 \mathrm{~min}$ versus $208.3 \mathrm{~min}$ ) and lesser blood loss (mean of $229 \mathrm{ml}$ versus $266.7 \mathrm{ml}$ ) (Table 2).

Regarding, the total consumption of fentanyl, it was found that patients in the HD group required the highest dose of fentanyl compared to those in the LD group (mean of $60 \mu \mathrm{g}$ versus $27 \mu \mathrm{g}$ ). Patients in the control group received no extra intraoperative narcotic doses (Table 2). This result showed high statistical significant difference $(p<0.001)$. On the other hand, total postoperative analgesic consumption during $1^{\text {st }}$ postoperative day was statistically insignificant between the 3 groups (Table 3). We didn't record any intra or postoperative complications among patients who participated in the study that could be associated with the use of TXA and so no patients were excluded from the study.

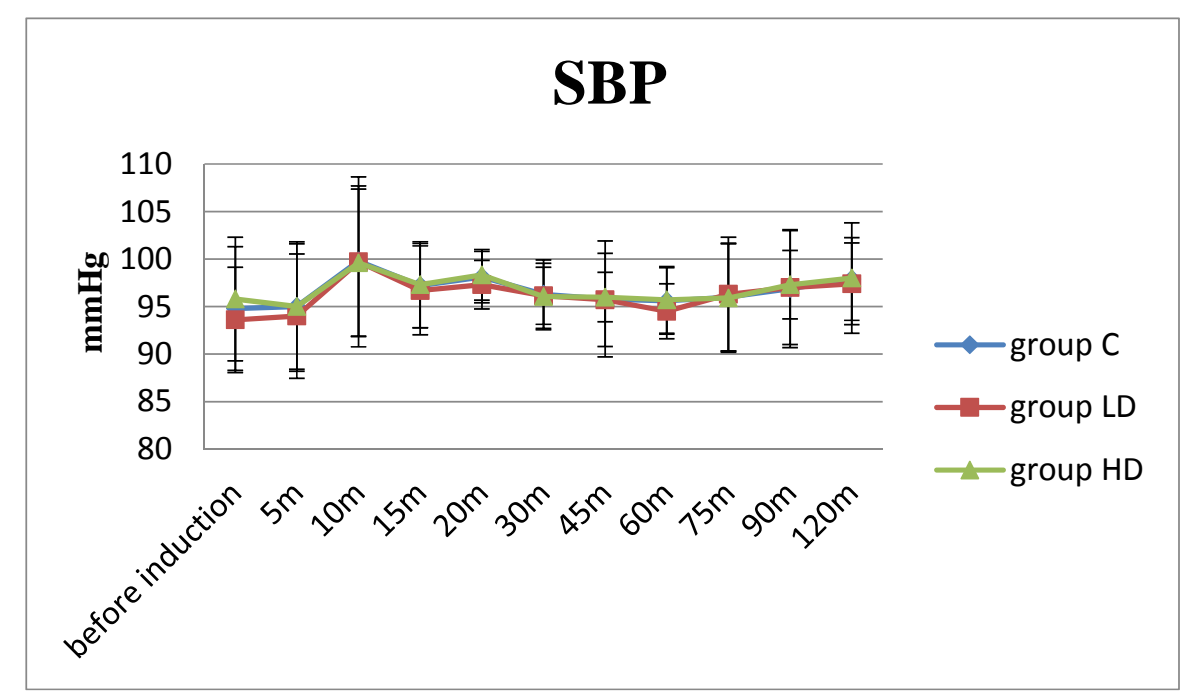

Fig. (1). Systolic Blood Pressure (SBP) variations throughout the operation Group $C=$ Control Group, Group LD $=$ Low dose tranexamic acid, Group HD = High dose tranexamic acid. 


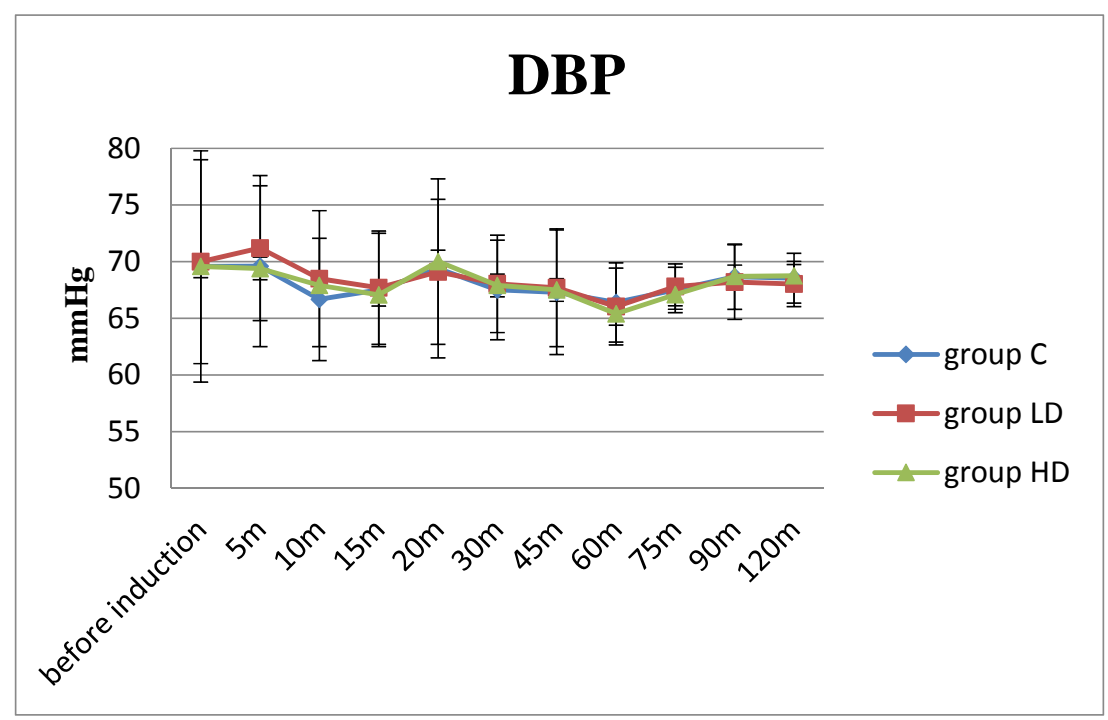

Fig. (2). Diastolic Blood Pressure (DBP) variations throughout the operation Group C $=$ Control Group, Group LD $=$ Low dose tranexamic acid, Group HD = High Dose tranexamic acid.

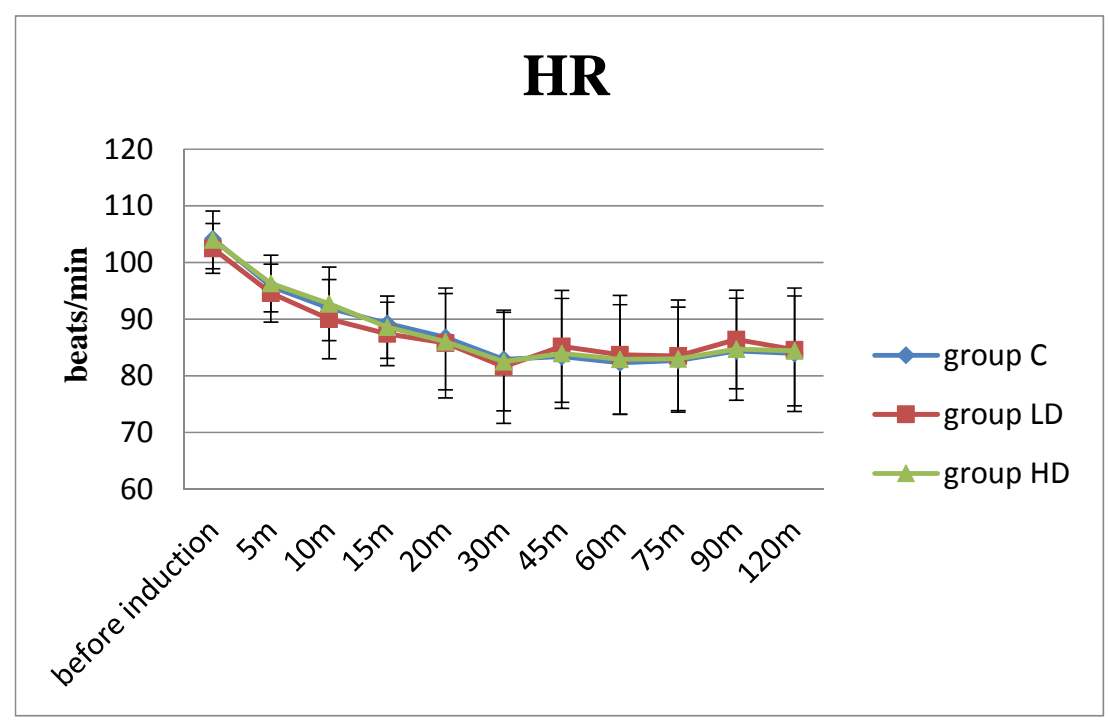

Fig. (3). Heart Rate (HR) variations throughout the operation Group $C=$ Control Group, Group LD = Low dose tranexamic acid, Group HD = High dose tranexamic acid.

Table 2. Comparison between the 3 study groups as regards the duration of surgery, intraoperative blood loss and intraoperative fentanyl consumption.

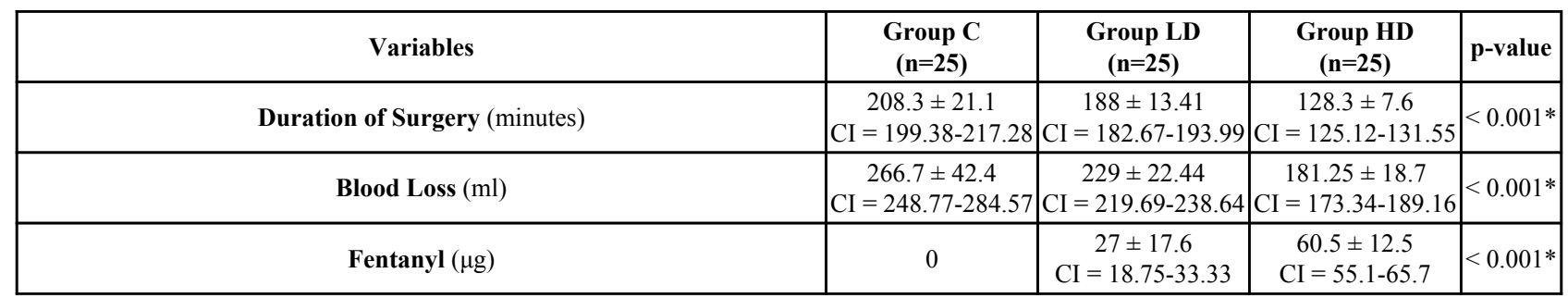

Data are presented as mean $\pm \mathrm{SD}$ and as mean $(95 \% \mathrm{CI})$

$* p<0.001$ is considered highly significant 
Table 3. Comparison between the 3 study groups as regards postoperative analgesic consumption during $1^{\text {st }} 24$ hours.

\begin{tabular}{|c|c|c|c|c|}
\hline \multirow[t]{2}{*}{ Postop analgesic consumption during $1^{\text {st }} 24$ hours (pethidine dose in $\mathrm{mg}$ ) } & $\begin{array}{c}\text { Group C } \\
(\mathrm{n}=25)\end{array}$ & $\begin{array}{c}\text { Group LD } \\
(\mathrm{n}=25)\end{array}$ & $\begin{array}{c}\text { Group HD } \\
(\mathrm{n}=25)\end{array}$ & p-value \\
\hline & $\begin{array}{c}\text { Mean }=66.5 \pm 16.58 \\
\text { CI }=59.46-73.46\end{array}$ & $\begin{array}{c}\text { Mean }=64.4 \pm 18.22 \\
\text { CI }=55.82-70.85\end{array}$ & $\begin{array}{c}\text { Mean }=66.4 \pm 18 \\
\text { CI }=58.49-74\end{array}$ & 0.896 \\
\hline
\end{tabular}

Data are presented as mean \pm SD and as mean $(95 \% \mathrm{CI})$

\section{DISCUSSION}

The current study demonstrated that TXA increased intraoperative analgesic requirements in a dose dependent manner in adolescent Egyptian patients undergoing elective single-stage posterior spine fusion surgery for idiopathic scoliosis but on the other hand, had decreased intraoperative blood loss and surgical operative time.

The results of the study didn't show significant differences between the three groups of patients as regards any of the recorded hemodynamic parameters at any of the observed time points. Similar results were obtained by Elwatidy et al. [12] who demonstrated hemodynamic stability between two groups of patients undergoing spinal surgery where one group received TXA to reduce perioperative blood loss and the other received placebo.

The current study findings verify the hypothesis that TXA might affect the analgesic requirement which was elucidated by the increased fentanyl consumption in the HD group $(60.5 \pm 12.5 \mu \mathrm{g})$ compared to the LD group $(27 \pm$ $17.6 \mu \mathrm{g}$ ) with a $\mathrm{p}$ value $<0.001$, while the control group didn't receive any added narcotics. Our results are in agreement with a recently published study by Ohashi and colleagues [8] in which patients who received TXA during the idiopathic scoliosis surgery required a higher infusion rate of analgesics. Though in their study, they included only two groups of patients, the first received remifentanil as an analgesic agent and the other did not. Also, Ohashi et al. [7] previously reported that TXA evoked behaviors indicative of spontaneous pain and mechanical allodynia in a concentration-dependent manner in rats. Their results indicated that TXA directly inhibited GABA and glycine receptors located at postsynaptic sites in spinal dorsal horn neurons, which increased neuronal excitability.

In the current study, the amount of blood loss decreased by TXA administration with the least amount in the HD group $(181.25 \pm 18.7 \mathrm{ml})$. The LD and the control groups showed more blood loss $(229 \pm 22.44 \mathrm{ml})$ and $(266.7 \pm 42.4$ $\mathrm{ml}$ ) respectively. Similar results were reported in earlier studies conducted on patients undergoing spinal surgeries [12 $15]$.

Our results showed shorter surgical duration in the HD group (mean of 128 min) compared to the LD and the control group (mean of 188 min versus 208 min respectively; $p<0.001$ ). Ohashi and colleagues [8] also showed similar data; Their TXA group had significant shorter surgical duration (mean of 267 minutes) when compared to their control group (mean of 320 minutes).

Patients in this study suffered none of the common intra or postoperative complications that could be attributed to TXA administration. Absence of deep venous thrombosis detection may be attributed to the short monitoring period in the study which extended up to 24 hours after the operation only. Yet, this was in accordance with previously published reports which didn't document any significant association between TXA use and increased risk of vascular complications whether TXA used was in a low dose $[12,14]$ or in a high dose $[16,17]$. Another theory why TXA did not increase the risk of thromboembolism is that TXA reduces blood loss by deactivating the fibrinolytic system, not by activating the coagulation cascade [14]. On the contrary, there were three thromboembolic complications, including one Pulmonary Embolism (PE) and two Deep Vein Thrombosis (DVTs) in Lin's and his colleagues [13] study which were all treated successfully with anticoagulation. There were no other complications as cases of myocardial infarction, seizure, stroke, or acute renal failure. A recent systematic review of 11 RCTs involving TXA in spinal surgery found only 1 case of myocardial infarction and no DVT or PEs [18]. Since the publication of that meta-analysis, Peters et al. reported 1 case complicated by PE in the TXA group of their RCT [19].

This study is not without its limitations. To begin with, the number of studied patients may not reveal all the complications owing to the relatively small sample size. Additionally, larger studies that include patients undergoing other surgical procedures will be needed to determine the incidence of untoward events associated with TXA use. Second, it's a single center study that included only Egyptian patients. Third, the anesthetic depth between patients was not compared owing to the lack of required equipment. Finally, subjective judgement (by the anesthesiologist) was used to guide the administration of intra operative fentanyl, which may have influenced our results. 


\section{CONCLUSION}

This study demonstrates that intraoperative administration of TXA increases the analgesic requirement during elective single stage posterior spine fusion surgery for idiopathic scoliosis which in turn reflects an increase in patients' intraoperative nociception.

\section{SOURCE OF FUNDING}

Declared none.

\section{ETHICS APPROVAL AND CONSENT TO PARTICIPATE}

The work was approved by the Ethics committee of ASUHs.

\section{HUMAN AND ANIMAL RIGHTS}

All experiment were carried out in accordance with the ethical guidelines of the Declaration of Helsinki, 1975 (https://www.wma.net/policies-post/wma-declaration- of-helsinki-ethical-principles-for-medical-research-involvinghuman-subjects/).

\section{CONSENT FOR PUBLICATION}

The study comprised 75 patients who participated in the study after informed consents have been obtained from their parents or their legal guardians.

\section{CONFLICT OF INTEREST}

The author declares no conflict of interest, financial or otherwise.

\section{ACKNOWLEDGEMENTS}

This study was done in the Surgical Department of Ain Shams University Educational Hospital, Cairo, Egypt.

\section{REFERENCES}

[1] Entwistle MA, Patel D. Scoliosis surgery in children. Contin Educ Anaesth Crit Care Pain 2006; 6: 13-6. [http://dx.doi.org/10.1093/bjaceaccp/mki063]

[2] Thakrar SV, Clevenger B, Mallett S. Patient blood management and perioperative anaemia. BJA Educ 2017; $17: 28-34$. [http://dx.doi.org/10.1093/bjaed/mkw061]

[3] Kuklo TR, Owens BD, Polly DW Jr. Perioperative blood and blood product management for spinal deformity surgery. Spine J 2003; 3(5): 388-93.

[http://dx.doi.org/10.1016/S1529-9430(02)00554-5] [PMID: 14588951]

[4] Verma K, Kohan E, Ames CP, et al. A comparison of two different dosing protocols for tranexamic acid in posterior spinal fusion for spinal deformity: A prospective, randomized trial. Int J Spine Surg 2015; 9: 65. [http://dx.doi.org/10.14444/2065] [PMID: 26767157]

[5] Pabinger I, Fries D, Schöchl H, Streif W, Toller W. Tranexamic acid for treatment and prophylaxis of bleeding and hyperfibrinolysis. Wien Klin Wochenschr 2017; 129(9-10): 303-16.

[http://dx.doi.org/10.1007/s00508-017-1194-y] [PMID: 28432428]

[6] Eroglu A, Solak M, Ozen I, Aynaci O. Stress hormones during the wake-up test in scoliosis surgery. J Clin Anesth 2003; $15(1)$ : 15-8. [http://dx.doi.org/10.1016/S0952-8180(02)00474-9] [PMID: 12657405]

[7] Ohashi N, Sasaki M, Ohashi M, Kamiya Y, Baba H, Kohno T. Tranexamic acid evokes pain by modulating neuronal excitability in the spinal dorsal horn. Sci Rep 2015; 5: 13458.

[http://dx.doi.org/10.1038/srep13458] [PMID: 26293582]

[8] Ohashi N, Ohashi M, Endo N, Kohno T. Administration of tranexamic acid to patients undergoing surgery for adolescent idiopathic scoliosis evokes pain and increases the infusion rate of remifentanil during the surgery. PLoS One 2017; 12(3): e0173622. [http://dx.doi.org/10.1371/journal.pone.0173622] [PMID: 28282425]

[9] Henry DA, Carless PA, Moxey AJ, et al. Anti-fibrinolytic use for minimising perioperative allogeneic blood transfusion. In: Henry DA, Ed. Cochrane Database Syst Rev. Chichester, UK: John Wiley \& Sons, Ltd 2011; p. CD001886. [http://dx.doi.org/10.1002/14651858.CD001886.pub3]

[10] Florentino-Pineda I, Thompson GH, Poe-Kochert C, Huang RP, Haber LL, Blakemore LC. The effect of amicar on perioperative blood loss in idiopathic scoliosis: The results of a prospective, randomized double-blind study. Spine 2004; 29(3): 233-8. [http://dx.doi.org/10.1097/01.BRS.0000109883.18015.B9] [PMID: 14752343] 
[11] Zufferey P, Merquiol F, Laporte S, et al. Do antifibrinolytics reduce allogeneic blood transfusion in orthopedic surgery? Anesthesiology 2006; 105(5): 1034-46. [http://dx.doi.org/10.1097/00000542-200611000-00026] [PMID: 17065899]

[12] Elwatidy S, Jamjoom Z, Elgamal E, Zakaria A, Turkistani A, El-Dawlatly A. Efficacy and safety of prophylactic large dose of tranexamic acid in spine surgery: A prospective, randomized, double-blind, placebo-controlled study. Spine 2008; 33(24): 2577-80. [http://dx.doi.org/10.1097/BRS.0b013e318188b9c5] [PMID: 19011538]

[13] Lin JD, Lenke LG, Shillingford JN, et al. Safety of a high-dose tranexamic acid protocol in complex adult spinal deformity: Analysis of 100 consecutive cases. Spine Deform 2018; 6(2): 189-94.

[http://dx.doi.org/10.1016/j.jspd.2017.08.007] [PMID: 29413743]

[14] Kushioka J, Yamashita T, Okuda S, et al. High-dose tranexamic acid reduces intraoperative and postoperative blood loss in posterior lumbar interbody fusion. J Neurosurg Spine 2017; 26(3): 363-7. [http://dx.doi.org/10.3171/2016.8.SPINE16528] [PMID: 27885960]

[15] Ng BKW, Chau WW, Hung ALH, Hui ACN, Lam TP, Cheng JCY. Use of Tranexamic Acid (TXA) on reducing blood loss during scoliosis surgery in Chinese adolescents. Scoliosis 2015; 10: 28. [http://dx.doi.org/10.1186/s13013-015-0052-9] [PMID: 26442124]

[16] Sethna NF, Zurakowski D, Brustowicz RM, Bacsik J, Sullivan LJ, Shapiro F. Tranexamic acid reduces intraoperative blood loss in pediatric patients undergoing scoliosis surgery 2005.

[17] Shapiro F, Zurakowski D, Sethna NF. Tranexamic acid diminishes intraoperative blood loss and transfusion in spinal fusions for duchenne muscular dystrophy scoliosis. Spine 2007; 32(20): 2278-83.

[18] Cheriyan T, Maier SP 2nd, Bianco K, et al. Efficacy of tranexamic acid on surgical bleeding in spine surgery: A meta-analysis. Spine J 2015. 15:752e61. doi: 10.1016/j.spinee.2015.01.013

[19] Peters A, Verma K, Slobodyanyuk K, et al. Antifibrinolytics reduce blood loss in adult spinal deformity surgery: A prospective, randomized controlled trial. Spine (Phila Pa 1976) 2015;40:E443e9. doi: 10.1097/BRS.0000000000000799.

\section{(C) 2018 Saleh et al.}

This is an open access article distributed under the terms of the Creative Commons Attribution 4.0 International Public License (CC-BY 4.0), a copy of which is available at: (https://creativecommons.org/licenses/by/4.0/legalcode). This license permits unrestricted use, distribution, and reproduction in any medium, provided the original author and source are credited. 